\title{
SOME EXTRALINGUAL VARIABLES OF L2 PHONIC COMPETENCE
}

The study assessed the relation between the overall degree of perceived foreign accent in non-natives' English speech and some extralingual factors. These variables include musical ability, phonic mimicry ability and type of personality. Five native speakers of English were asked to auditorily evaluate the samples of free English speech produced by each of 79 non-native talkers using the equal-appearing interval scale. The 5-point scale was used to rate each of the variables for each non-native speaker and the interclass correlation coefficients were calculated to identify the most important predictors of L2 pronunciation quality. The findings reported may be important for the learning and teaching second languages.

\section{Introduction}

This paper reports research which attempts to identify factors which explain the variance in a second language (L2) phonic competence. The authors investigate the influence and interrelatedness of extralingual variables (musical ability, phonic mimicry ability and type of personality), usually considered significant in foreign language acquisition, especially on the level of phonology, i. e. in acquiring the phonological subsystem of a foreign language. The data collected in empirical research presented in this paper show that, although the influence of some of these variables is debatable, it is not always possible to single out one of them and to disregard the rest of them. It is not always possible to say which of these influences will prevail under some circumstances either. The acquisition of a phonological system is an immensely complex process, influenced by numerous factors simultaneously. We tried to "capture" the possible influence of three potentially relevant factors, usually intuitively recognised, by professionals and laymen alike, as highly influential.

For the last 40 years, beginning with the classic article of Asher and García [1], the variety of variables influencing the acquisition of the phonological system of a foreign language has been investigated in a large number of experimental studies. Although considerable individual variation can be observed in adults' mastery of L2 production and perception, the L2 literature, as well as our common experience as language users, generally indicates the most adult L2 learners will permanently speak the L2 with a foreign accent. One interpretation of this observation is, in the scientific study of foreign accent, that success in acquiring the phonetics and phonology of an L2 is dependent on a number of variables which influence the performance of individual L2 users. Identifying such factors may be important for the teaching and learning foreign languages. The studies of the issue published so far differ greatly in terms of the languages, subjects, methods or procedures examined. These differences appear to be responsible for the often divergent results of the studies. The relative importance of many factors is uncertain because many variables relating to subject characteristics tend to be confounded, and because of the lack of adequate experimental control in some studies.

\section{Acquisition of $\mathrm{L} 2$ pronunciation}

\subsection{L2 pronunciation research}

The acquisition of the phonetic/phonological component in a second language is a complex and dynamic process which is influenced by the context and conditions in which the language is learned. The overall quality of L2 pronunciation is likely to vary depending on the characteristics of the subjects. The subjects examined in previous studies have differed in a number of potentially important ways. Most previous studies have examined English as the target $\mathrm{L} 2$ being learned. The native languages spoken by the subjects have been far more diverse. The nonnative subjects mostly differed in L2 experience, the age of L2 onset, the length of residence in L2-speaking country, the degree of motivation to speak an L2 and many other variables [e.g., 2 - 11]. The fact that the subjects examined in previous research differed along the dimensions just described often makes direct comparisons across studies problematic. Thus, this should not lead one to conclude that the degree of L2 pronunciation accuracy cannot be scaled reliably and validly.

The studies of the overall degree of L2 foreign accent have also differed in terms of the techniques used to elicit nonnative speech samples. In most studies, subjects have been asked to read words, sentences or paragraphs [e.g., 1, 3, 7]. In a number of

\footnotetext{
* Zdena Kralova ${ }^{1}$, Eva Skorvagova ${ }^{2}$, Juraj Ruttkay ${ }^{3}$, Faculty of Science, University of Zilina, Slovakia

${ }^{1}$ Department of English Language and Literature, E-mail: zdena.kralova@fpv.uniza.sk

${ }^{2}$ Department of Pedagogy, Psychology and Social Science

${ }^{3}$ Department of Music
} 
studies, subjects have also been asked to produce samples of free (i. e., extemporaneous) L2 speech [e.g., 12 - 15]. And finally there have been studies in which subjects were asked to repeat speech materials after hearing a native speaker model in a direct repetition technique [8] or a delayed repetition technique [16]. Some researchers have used more than one elicitation technique [e.g., $12,14,17]$.

A control group of native speakers was recruited in most of the studies cited so far in addition to groups of nonnative subjects. The numbers of raters used in various L2 pronunciation studies have differed greatly, ranging from just one [18] to 85 [19]. It is not known at present how many raters are needed to provide a reliable estimate. Unfortunately, not all the studies have included a native group [20,21]. This may lead to several problems - for example, it remains uncertain how the native speaker would performed under the specific circumstances of a particular experiment. One important methodological question pertains to the characteristics of the listeners. In some studies, naive raters were recruited to evaluate speech samples [e.g., 1, 8]. In other studies, "expert" raters such as linguists or teachers have participated [e.g., 15, 22]. [14] reported that experienced raters generally perceived a higher degree of L2 foreign accent in nonnative speech than inexperienced raters, while [7] found no significant differences between experienced and inexperienced raters. In Slovakia it seems to be a problem to recruit the homogeneous group of English native speakers who would be willing to participate in an experiment (often time consuming one) and who would not be trained or experienced EFL teachers.

The listeners who evaluate $\mathrm{L} 2$ speech usually use a rating scale to indicate the quality of $\mathrm{L} 2$ pronunciation they perceive in a speech sample. No standard scale for measuring the accuracy of L2 pronunciation has been developed so far. The equal-appearing interval (EAI) scales differ in resolution. A 5-point scale has been used most commonly [e. g., 7, 12, 13]. [8, 22] employed a continuous scale to evaluate foreign accent. [23] carried out a research to determine whether foreign accent is a metathetic continuum (a continuum that can be divided into equal intervals ranging from high to low) or a prothetic continuum (a continuum that is not amenable to linear partitioning). They indicated that foreign accentedness is a metathetic continuum, which means that it is appropriate to use an EAI scale and found that a 9-point (or 11-point) scale should be used to rate L2 speech samples for degree of foreign accent.

\subsection{Factors influencing L2 pronunciation}

The differences between studies in design and methodology have led researchers to draw rather conflicting conclusions about the influence of certain factors on L2 pronunciation. The factors that received the most attention in the literature are undoubtedly the L2 onset age and the length of stay in an L2-speaking environment. Unfortunately, hardly any study in the existing literature
[24] has examined the changes in degree of L2 pronunciation accuracy in a longitudinal design. Affective and social factors as well as individual aptitude have been seen as possible predictors of the second language phonetic performance [2]. Contact with native speakers has also been reported as having a significant influence on the second language pronunciation $[14,25,26]$. Specific phonetic training has generally been found to be positively associated with phonetic development in L2. Other factors such as attitudinal and motivational variables have sometimes - though not always - proved to be influential [14]. A number of other factors related to the speakers' backgrounds, including gender [1, 8, 14], mimicry ability $[14,25,26]$ and professional motivation [27] have also been found to be significantly correlated with global accentedness scores in at least some studies. These results, however, have not been consistently replicated, and require further examination before any firm conclusions can be drawn.

\section{Musical ability}

Musical ability has as yet not been identified as one of those variables that have an important influence on L2 pronunciation quality [14]. However, some hypotheses assume that there is a positive correlation between music perception/production and the perception/production of the sounds of L2. It has been partly verified that there is a significant correlation between music production and the production of vowels [20]. Singing talent has been linked to the ability to mimic pronunciation by [8]. [28] has demonstrated that this skill is not improved by musical training and so there is a chance that it is innate and cannot be altered by education.

\section{Mimicry ability}

Pronunciation is generally taught on the basis that imitation is the natural mechanism for its acquisition. Except for one study [8] the ability to mimic unfamiliar speech sounds has repeatedly been identified as a significant predictor of $\mathrm{L} 2$ pronunciation quality $[14,25,26]$. The imitation paradigm [29] has shown that subjects shift their production in the direction of the target, indicating the use of episodic traces in speech perception. Recent studies have shown that traces of episodic memory are retained and used in speech perception, and that both speech perception and production are more plastic than previously considered [e. g., 30].

\section{Type of personality}

Findings from several studies [e.g., 31] showed that anxiety significantly contributes to students' success in learning L2. This affective dimension of L2 learning involves having difficulty concentrating in the class, feeling afraid, embarrassed or uncomfortable to speak in L2. Extroversion and introversion have been discussed as personality factors in second language learning [e.g., 32], though the contribution of either factor to learning is not clear. Personality factors such as self-esteem, inhibition, anxiety, risktaking and extroversion, are thought to influence second language learning because they can contribute to motivation and the choice of learning strategies. 


\section{Methodology}

\section{Speakers}

Seventy-nine ( 59 female and 20 male) subjects examined in the study were Slovak first-year university students enrolled in the English Language and Literature course. They were approximately at an intermediate level of English proficiency, aged between 18 and 20 and had typically started learning English at elementary school with a focus on grammar-based instruction. The majority of them had never lived in an English-speaking country.

Assessors

5 native English control subjects ( 3 American - 2 male, 1 female; 2 British - 1 male, 1 female) were asked to auditorily evaluate the English texts produced by each of the 79 talkers. The raters were English native speakers more or less experienced in ELT who had lived in Slovakia for several months/years.

The assessor of musical ear and memory test was an expert musician, the assessor of the phonic mimicry ability test was a phonetician and the marker of the personality questionnaire was a psychologist (Table 1). All assessors were asked to use a five-point scale to indicate the degree of relevant material and to rate each talker by a mark on a scale from 1 (low) to 5 (high) (Table 2).

\section{Material}

Pronunciation samples (a free, extemporaneous talk in English), direct phonic imitation and musical tasks were recorded on a recorder with a condense microphone for further analysis and reference. The collection took place in classrooms at the University of Zilina and required approximately 25 minutes for each student. The information concerning personality was elicited from the participants by the way of a questionnaire which required 50 minutes to complete (Table1).

\section{Procedure}

Relying on the data most frequently presented in research papers and theoretical discussions, we aimed primarily at investigating the possible influence of three extralingual factors ${ }^{1)}$ (EF1 - musical ability, EF2 - phonic mimicry ability, EF3 - type of personality) upon the pronunciation accuracy observed in the interlanguage of learners of English as a foreign language.

Native speakers were asked to auditorily evaluate the samples of free English speech ( 3 minutes) produced by each of the nonnative talkers using the equal-appearing interval 5-point scale. An average rating was obtained for each speaker and the variable English phonic competence (EPC) was computed by averaging across each rater`s score.

The musical ability of the subject was tested in a basic test of musical ear and memory (10 minutes). The test was performed and assessed by a musician in a 5-point scale. The English words and phrases were modelled on the tape and repeated immediately afterwards to test the direct mimicry ability (10 minutes). The 16 factor questionnaire [33] was administered in a group form without any time limit given. Scoring was processed using Psychosoft System Brno. The global personality factor EX Extroversion appeared to be the most important for the profile interpretation.

The data were collected, then evaluated. The interclass correlation coefficients ( $r$ ) were calculated to identify the significant predictors of L2 pronunciation quality (Table 3 ). To assess their relative contribution to EPC, the variables were submitted to a simple correlation. Correlation coefficients were calculated for each factor by applying the scoring coefficients generated by the principal component analysis to standardized values for subjects' responses. The variables were correlated with the total pronunciation rating and the correlation coefficients (r) were obtained. The result is statistically relevant for the phenomena with the correlation coefficients higher than the critical values for the variable length 79 on the 0.05 level $=0.2787$. For lower values the correlation is not evident. The closer is the value to 1.0 , the stronger is the correlation between the variables.

\section{Results}

Testing methods

Tab. 1

\begin{tabular}{|l|l|l|}
\hline Extralingual factor & Abbr. & Testing method \\
\hline musical ability & EF1 & perceptual assessment (J. Ruttkay) \\
\hline phonic mimicry ability & EF2 & perceptual assessment (Z. Kralova) \\
\hline type of personality & EF3 & $\begin{array}{l}\text { 16-factor personality questionnaire } \\
\text { (E. Skorvagova) }\end{array}$ \\
\hline
\end{tabular}

Evaluation scale

Tab. 2

\begin{tabular}{|c|c|c|c|c|c|}
\hline \multicolumn{5}{|l|}{ Evaluation scale } \\
\hline & 5 & 4 & 3 & 2 & 1 \\
\hline EPC & excellent & very good & good & average & poor \\
\hline EF1 & excellent & very good & good & average & poor \\
\hline EF2 & excellent & very good & good & average & poor \\
\hline & $\begin{array}{c}\text { extrovert } \\
(10-8 \\
\text { EF3 }\end{array}$ & $\begin{array}{c}\text { neutral } \\
(7 \text { points })\end{array}$ & $\begin{array}{c}\text { neutral } \\
(5-6 \\
\text { points })\end{array}$ & $\begin{array}{c}\text { neutral } \\
(4 \text { points })\end{array}$ & $\begin{array}{c}\text { introvert } \\
(3-1 \\
\text { points })\end{array}$ \\
\hline
\end{tabular}

\footnotetext{
1) intralingual factors - characteristics related to a language system; paralingual factors - temporal characteristics partly related to a language system; extralingual factors - characteristics not related to a language system;
} 
Correlation of EPC and EF

\begin{tabular}{|c|c|c|c|c|}
\hline \multirow{2}{*}{ Student } & \multirow{2}{*}{ EPC } & \multicolumn{3}{|c|}{ Extralingual factors } \\
\hline & & EF1 & EF2 & EF3 \\
\hline 1 & 2.6 & 3 & 3 & 4 \\
\hline 2 & 3.2 & 5 & 4 & 3 \\
\hline 3 & 2 & 3 & 3 & 2 \\
\hline 4 & 2.2 & 2 & 2 & 4 \\
\hline 5 & 2 & 1 & 2 & 4 \\
\hline 6 & 1.6 & 2 & 1 & 4 \\
\hline 7 & 2.2 & 1 & 2 & 3 \\
\hline 8 & 2.4 & 3 & 3 & 4 \\
\hline 9 & 2.4 & 3 & 2 & 3 \\
\hline 10 & 1.8 & 3 & 4 & 2 \\
\hline 11 & 2.2 & 2 & 3 & 2 \\
\hline 12 & 2.2 & 5 & 1 & 4 \\
\hline 13 & 1.6 & 5 & 4 & 5 \\
\hline 14 & 3.6 & 4 & 2 & 4 \\
\hline 15 & 3.2 & 3 & 4 & 3 \\
\hline 16 & 1.8 & 3 & 3 & 3 \\
\hline 17 & 3.4 & 5 & 4 & 4 \\
\hline 18 & 3.2 & 5 & 5 & 3 \\
\hline 19 & 2.8 & 5 & 3 & 4 \\
\hline 20 & 2.8 & 4 & 3 & 3 \\
\hline 21 & 2 & 2 & 1 & 3 \\
\hline 22 & 2 & 2 & 2 & 3 \\
\hline 23 & 1.6 & 1 & 4 & 2 \\
\hline 24 & 2.6 & 5 & 5 & 3 \\
\hline 25 & 4.4 & 3 & 5 & 5 \\
\hline 26 & 1.6 & 1 & 1 & 3 \\
\hline 27 & 2.6 & 2 & 3 & 4 \\
\hline 28 & 1.8 & 4 & 1 & 2 \\
\hline 29 & 2.8 & 5 & 3 & 4 \\
\hline 30 & 2.8 & 1 & 3 & 4 \\
\hline 31 & 2 & 4 & 3 & 3 \\
\hline 32 & 3.4 & 3 & 3 & 4 \\
\hline 33 & 3.2 & 4 & 2 & 5 \\
\hline 34 & 2.2 & 2 & 3 & 4 \\
\hline 35 & 2.4 & 2 & 4 & 3 \\
\hline 36 & 2.8 & 3 & 1 & 2 \\
\hline 37 & 2.4 & 1 & 2 & 4 \\
\hline 38 & 3.8 & 5 & 5 & 2 \\
\hline 39 & 3.2 & 2 & 1 & 3 \\
\hline 40 & 2.4 & 3 & 4 & 5 \\
\hline 41 & 3.2 & 5 & 3 & 3 \\
\hline 42 & 4.6 & 5 & 5 & 4 \\
\hline 43 & 2.6 & 4 & 3 & 3 \\
\hline 44 & 1.4 & 2 & 2 & 4 \\
\hline 45 & 2.6 & 1 & 3 & 4 \\
\hline 46 & 3.4 & 1 & 3 & 2 \\
\hline 47 & 3 & 4 & 4 & 2 \\
\hline 48 & 2.6 & 2 & 1 & 3 \\
\hline 49 & 2.4 & 3 & 1 & 4 \\
\hline 50 & 3.4 & 5 & 2 & 3 \\
\hline 51 & 2.4 & 3 & 1 & 3 \\
\hline
\end{tabular}

\begin{tabular}{|c|c|c|c|c|}
\hline 52 & 3 & 2 & 1 & 3 \\
\hline 53 & 2.2 & 1 & 2 & 3 \\
\hline 54 & 2.8 & 3 & 2 & 3 \\
\hline 55 & 2.4 & 2 & 4 & 4 \\
\hline 56 & 3.4 & 3 & 2 & 3 \\
\hline 57 & 2.8 & 2 & 1 & 3 \\
\hline 58 & 1.6 & 1 & 4 & 4 \\
\hline 59 & 2.6 & 2 & 2 & 3 \\
\hline 60 & 3.2 & 5 & 3 & 3 \\
\hline 61 & 2.4 & 4 & 1 & 3 \\
\hline 62 & 2.4 & 1 & 4 & 2 \\
\hline 63 & 3.4 & 1 & 5 & 4 \\
\hline 64 & 3 & 1 & 1 & 4 \\
\hline 65 & 2 & 1 & 3 & 3 \\
\hline 66 & 2.6 & 3 & 3 & 4 \\
\hline 67 & 2.6 & 1 & 1 & 3 \\
\hline 68 & 3.4 & 1 & 2 & 3 \\
\hline 69 & 3.6 & 1 & 3 & 4 \\
\hline 70 & 1.8 & 1 & 1 & 3 \\
\hline 71 & 2.6 & 5 & 2 & 4 \\
\hline 72 & 2 & 5 & 3 & 3 \\
\hline 73 & 3 & 2 & 1 & 4 \\
\hline 74 & 1.8 & 3 & 4 & 3 \\
\hline 75 & 2.2 & 4 & 1 & 4 \\
\hline 76 & 1.4 & 5 & 1 & 2 \\
\hline 77 & 2.8 & 3 & 2 & 3 \\
\hline 78 & 2.6 & 3 & 4 & 3 \\
\hline 79 & 2.4 & 2 & 3 & 3 \\
\hline Mean & 2.59 & 2.85 & 2.63 & 3.32 \\
\hline $\mathbf{r}$ & - & 0.2298 & 0.2881 & 0.1387 \\
\hline
\end{tabular}

\section{Conclusions}

Preliminary analysis revealed that much the same EPC ratings were provided by the five raters. The mean for all the native speaker evaluations was 2.59 and there was a standard deviation of 0.73 . Initially, the three measured variables were correlated with the total pronunciation ratings ( 0.2787 on the 0.05 level). These produced the following correlations:

$$
\begin{array}{ll}
\text { EF1 (musical ability) } & r=0.2298 \\
\text { EF2 (mimicry ability) } & r=0.2881 \\
\text { EF3 (type of personality) } & r=0.1387
\end{array}
$$

The correlation between EPC and the factors is rather weak. The results show that only one of the factors (EF2) proved relevant for the differences in the foreign language pronunciation rating and no statistically significant correlation could be established between the variables EF1 and EF3.

The study assessed the relation between the overall degree of the perceived foreign accent in non-natives' English speech and three extralingual factors which are supposed to affect L2 pronuncia- 
tion. The empirical data clearly indicated that the so-called foreign accent phenomenon is a highly complex one. Namely, it is not always possible to detect a clear corelation between the observed level of phonic performance of a foreign language learner and any of the factors usually considered crucial for the foreign accent reduction. Thus it is not always possible to isolate those variables which are considered the most important. The mutual influence of a number of factors appears to be so complex that the influence of each and every one of them cannot be singled out and analysed independently, without taking all the others into consideration.
Note, however, that longitudinal research is needed to determine more precisely at what point in L2 learning, if any, the individual factors cease to have an effect on the pronunciation of L2. The results found in this study could prove to be of interest for language teaching methodology as it should be the goal of L2 teachers to find the most efficient methodology for L2 (not only pronunciation) learning that would take into consideration the individual differences between students, thus making the acquisition of L2 a more effective, enjoyable and less frustrating experience.

\section{References}

[1] ASHER, J. J., GARCIA, R.: The Optimal Age to Learn a Second Language, The Modern Language Journal, vol. 53, 3/1969, p. $334-341$.

[2] FLEGE, J. E.: A Critical Period for Learning to Pronounce Foreign Languages, Applied Linguistics, vol. 8, 2/1987, p. 162-177.

[3] FLEGE, J. E.: Factors Affecting Degree of Perceived Foreign Accent in English Sentences, Journal of the Acoustical Society of America, vol. 84, 1/1988, p. 70-79.

[4] SINGLETON, D.: Language Acquistion: the Age Factor, Clevedon: Multilingual Matters Ltd., 323 p., 1989.

[5] PATKOWSKI, M. S.: Age and Accent in a Second Language, Reply to James Emil Flege, Applied Linguistics, vol. 11, 1/1990, p. 73-89.

[6] FLEGE, J. E.: Perception and Production: the Relevance of Phonetic Input to L2 Phonological Learning, Crosscurrents in Second Language Acquisition, T. Heubner and C. A. Ferguson (eds.). Philadelphia: John Benjamins, p. 249-289, 1991.

[7] BONGAERTS, T., VAN SUMMEREN, C., PLANKEN, B., SCHILS, E.: Age and Ultimate Attainment in the Pronunciation of a Foreign Language, Studies in Second Language Acquisition, vol. 19, 4/1997, p. 447-465.

[8] FLEGE, J. E., MUNRO, M. J., MacKAY, I. R. A.: Factors Affecting Strength of Perceived Foreign Accent in a Second Language, Journal of the Acoustical Society of America, vol. 97, 5/1995, p. 3125-3134.

[9] BIALYSTOCK, E.: The Structure of Age: in Search of Barriers to SLA, Second Language Research, vol. 13, 2/1997, p. 116-137.

[10] FLEGE, J. E., FRIEDA, E. M., NOZAWA, T.: Amount of Native-Language (L1) Use Affects the Pronunciation of an L2, Journal of Phonetics, vol. 25, 2/1997, p. 169-186.

[11] PISKE, T., MacKAY, I. R. A., FLEGE, J. E.: Factors Affecting Degree of Foreign Accent in an L2: a Review, Journal of Phonetics, vol. 29, 1/2001, p. 191-215.

[12] OYAMA, S.: The Sensitive Period for the Acquisition of a Nonnative Phonological System, Journal of Psycholinguistic Research, vol. 5, 3/1976, p. 261-283.

[13] PIPER, T., CANSIN, D.: Factors Influencing the Foreign Accent, The Canadian Modern Language Review, vol. 44, 3/1988, p. 334-342.

[14] THOMPSON, I.: Foreign Accents Revisited: the English Pronunciation of Russian Immigrants, Language Learning, vol. 41, 2/1991, p. 177-204.

[15] KRALOVA, Z.: Slovak-English Phonic Interference (in Slovak), Faculty of Science, University of Zilina, 100 p., 2005.

[16] FLEGE, J. E., YENI-KOMSHIAN, G., LIU, H.: Age Constraints on Second Language Acquisition, Journal of Memory and Language, vol. 41, 1/1999, p. 78-104.

[17] MARKHAM, D.: Phonetic Imitation, Accent, and the Learner, Lund: Lund University Press, 1997, 269 p.

[18] SNOW, C. E., HOEFNAGEL-HOHLE, M.: Age Differences in the Pronunciation of Foreign Sounds, Language and Speech, vol. 20, 3/1977, p. 357-365.

[19] NEUFELD, G. G.: Towards a Theory of Language Learning Ability, Language Learning, vol. 29, 2/1979, p. 227-241.

[20] TAHTA, S., WOOD, M., LOEWENTHAL, K.: Foreign Accents: Factors Relating to Transfer of Accent from the First Language to a Second Language, Language and Speech, vol. 24, 2/1981, p. 265-272.

[21] ELLIOT, R. E.: Field Independence/Dependence, Hemispheric Specialization, and Attitude in Relation to Pronunciation Accuracy in Spanish as a Foreign Language, The Modern Language Journal, vol. 79, 3/1995, p. 356-371.

[22] FLEGE, J. E., FLETCHER, K. L.: Talker and Listener Effects on Degree of Perceived Foreign Accent, Journal of the Acoustical Society of America, vol. 91, 1/1992, p. 370-389.

[23] SOUTHWOOD, M. H., FLEGE, J. E.: Scaling Foreign Accent: Direct Magnitude Estimation Versus Interval Scaling, Clinical Linguistics and Phonetics, vol. 13, 5/1999, p. 335-449.

[24] MEADOR, D., FLEGE, J. E., Mac KAY, I. R. A.: Factors Affecting the Recognition of Words in a Second Language, Bilingualism: Language and Cognition, vol. 3, 1/2000, p. 55-67.

[25] SUTER, R. W.: Predictors of Pronunciation Accuracy in Second Language Learning, Language Learning, vol. 26, 2/1976, p. $233-253$. 
[26] PURCELL, E. T., SUTER, R. W.: Predictors of Pronunciation Accuracy: An Examination, Language Learning, vol. 30, 2/1980, p. 271-187.

[27] MOYER, A.: Ultimate Attainment in L2 Phonology, Studies in Second Language Acquisition, vol. 21, 1/1999, p. 81-108.

[28] MORGAN, C.: Musical Aptitude and Second-Language Phonetics Learning: Implications for Teaching Methodology, Simon Fraser University, PhD Thesis, 2003.

[29] GOLDINGER, S. D.: Echoes or Echoes? An Episodic Theory of Lexical Access, Psychological Review, vol. 105, 2/1998, p. 251-279.

[30] SHOCKLEY, K., SABADINI, L., FOWLER, C. A.: Imitation in Shadowing Words, Perception and Psychophysics, vol. 66, 3/2004, p. 422-429.

[31] SEMMAR, Y.: An Exploratory Study of Motivational Variables in a Foreign Language Learning Context, Journal of Language and Learning, vol. 4, 1/2006, p. 118-132.

[32] RICHARDS, J. C., PLATT, J., PLATT, H.: Longman Dictionary of Language Teaching and Applied Linguistics. Harlow: Pearson Education Limited, 2002

[33] CATElL, R. B., CATElL, A. K., CATELL, H. E. P.: 16-factor Personality Questionnaire (in Slovak), Bratislava: Psychodiagnostika, 1997. 